\title{
Enhancement of neutrophil function by the bronchial epithelium stimulated by epidermal growth factor
}

\author{
M. Uddin*, G. Seumois*, L.C. Lau*, P. Rytila”, D.E. Davies* and R. Djukanović*
}

ABSTRACT: The bronchial epithelium is an important physical barrier that regulates physiological processes including leukocyte trafficking. The aim of the present study was to elucidate the mechanisms whereby the bronchial epithelium, stimulated by epidermal growth factor (EGF) as part of a response to acute or chronic injury, could activate and chemoattract human neutrophils.

Subconfluent human bronchial epithelial (16HBE) cells were stimulated with EGF to mimic the in vivo events after injury. The effect of the resulting EGF-conditioned media (CM) was compared with that of basal-CM with respect to neutrophil activation and chemotaxis. Such findings were then confirmed using primary bronchial epithelial cells (PBECs) from healthy volunteers.

EGF-CM from 16HBE cells caused increased expression of CD11b/CD66b and CD62L loss on neutrophils when compared with basal-CM. EGF-CM contained significant neutrophil chemotactic activity involving granulocyte-macrophage colony-stimulating factor and interleukin-8 that was potentiated by leukotriene $B_{4}$. This was dependent on neutrophil phosphatidylinositol-3-kinase activation and Akt phosphorylation, with partial regulation by phospholipase D, but not mammalian target of rapamycin. Consistent with these observations, EGF-CM derived from PBECs displayed increased chemotactic activity.

The present results suggest that the enhanced chemotactic activity of the epidermal growth factor-conditioned epithelium can enhance neutrophil-mediated immunity during acute injury, while during continued injury and repair, as in chronic asthma, this could contribute to persistent neutrophilic inflammation.

KEYWORDS: Bronchial epithelium, chemotaxis, epidermal growth factor, inflammation, lung, neutrophils

$\mathbf{N}$ eutrophil-mediated inflammation is the subject of extensive research [1]. Influx of neutrophils into tissues begins by rolling, which is mediated via surface CD62L (L-selectin) interacting with complementary ligands on endothelial cells, and is followed by firm neutrophil adhesion to the endothelium using $\beta_{2}$-integrins (CD11a and CD11b) and transmigration. Upon activation, neutrophils shed CD62L and increase surface expression of CD11b [2,3] and CD66b [4]. This is accompanied by degranulation, respiratory burst $[5,6]$ and release of a range of proinflammatory agents $[1,5,7]$. Neutrophil-mediated inflammation occurs during acute infection, in acute respiratory distress syndrome [8] and in chronic diseases, such as chronic obstructive pulmonary disease [9]. Increasingly, neutrophils are being implicated in asthma [10], a disorder long viewed as an eosinophilic disease [11]. Thus, emerging evidence points to their role during infectious exacerbations and in severe chronic asthma [12-14]. Raised numbers are observed in bronchoalveolar lavage (BAL), induced sputum and both bronchial and transbronchial biopsies [7, $12,15]$ with increased concentrations of neutrophilactive mediators interleukin (IL)-8 [13, 16], leukotriene $(\mathrm{LT}) \mathrm{B}_{4}[16,17]$, granulocyte-macrophage colony-stimulating factor (GM-CSF) $[18,19]$ and tumour necrosis factor (TNF)- $\alpha[18,20]$ in BAL.

The mechanisms regulating the accumulation and activation of neutrophils in the airways

\section{AFFILIATIONS}

*Allergy and Inflammation Research, Division of Infection, Inflammation and Repair, School of Medicine,

Southampton, UK.

"Division of Allergy, Helsinki

University Central Hospital, Helsinki, Finland.

CORRESPONDENCE

M. Uddin

Allergy and Inflammation Research University of Southampton School of Medicine

Level F

South Academic Block

Mailpoint 810

Southampton

S016 6YD

UK

Fax: 442380701771

E-mail: M.Uddin@soton.ac.uk

Received:

November 012007

Accepted after revision:

December 072007

SUPPORT STATEMENT

This research was funded by the British Lung Foundation (Project Grant: P04/14)

STATEMENT OF INTEREST

A statement of interest for D.E. Davies and R. Djukanović, and for the study itself can be found at www.erj.ersjournals.com/misc/ statements.shtml 
remain poorly understood but are increasingly thought to involve the bronchial epithelium and growth factors such as epidermal growth factor (EGF), which acts via the EGF receptor (EGFR), a member of the ErbB family (c-erbB1, HER1; c-erbB2, HER2, neu; c-erbB3, HER3; and c-erbB4, HER4) [21, 22]. In addition to its role in epithelial regeneration and repair [22], the EGFR pathway is believed to contribute to lung inflammation [23, 24]. Extensive immunostaining for EGFR in the asthmatic bronchial epithelium has previously been reported to be increased with disease severity and to correlate with IL-8 expression [25]. These data are consistent with observations that activation of the EGFR pathway causes IL-8 secretion [24, 26, 27] and provides a mechanism for neutrophil migration. EGFR-mediated mechanisms have also been implicated in bronchial epithelial repair in asthma $[22,28]$, augmenting the inflammatory potential of virusinfected bronchial epithelial cells [29] and modulating the effects of cigarette smoke [26]. Previous studies have reported that primary bronchial epithelial cell (PBEC) cultures derived from asthmatic patients release neutrophil-active mediators IL-8, GM-CSF and TNF- $\alpha$ [24, 30, 31]. Furthermore, there is evidence that EGF induces a corticosteroidinsensitive increase in IL- 8 gene and protein expression by bronchial epithelial cells [24, 25] and a strong correlation exists between epithelial EGFR expression and both epithelial IL-8 immunostaining and neutrophil numbers has been demonstrated [24].

The functional significance of the augmented production of pro-inflammatory mediators and their relative roles in driving neutrophilic inflammation remain uncharacterised. Furthermore, little is known about the intracellular neutrophil signalling pathway(s) involved in the communication between the epithelium and neutrophils. The current authors hypothesised that exposure of bronchial epithelial cells to EGF induces pro-inflammatory factors that promote activation and recruitment of neutrophils and that this activation involves phosphatidylinositol-3-kinase (PI3K) and its downstream pathway. In healthy subjects, EGFRs are localised on the basolateral surfaces of epithelial cells where they are inaccessible to ligands in the airway lining fluid. However, damage to the barrier allows ligand penetration and subsequent EGFR activation. To test this hypothesis, the authors first used the human bronchial epithelial (16HBE) 14o-HBE cell line stimulated by EGF to mimic the activation that occurs when the epithelial barrier is damaged. Studies have shown that $16 \mathrm{HBE}$ cells display morphological, functional and permeability properties resembling those of the primary bronchial epithelium [32-34]. It was examined whether when the epithelium was switched into repair mode by EGF it could modulate neutrophil function by studying the ability of conditioned media from EGF-stimulated epithelium (EGF-CM) to activate and chemoattract neutrophils and to trigger signalling pathways in neutrophils. After showing major effects of EGFR on the way $16 \mathrm{HBE}$ cells modulate neutrophil function, the chemotaxis experiments were repeated using PBECs from healthy nonatopic individuals as a source of conditioned media (CM) to confirm that the observations seen in the cell line were reflective of the function of primary cells derived from volunteer subjects.

\section{MATERIALS AND METHODS}

\section{Epithelial cell culture}

The 16HBE epithelial cells and fresh PBECs, obtained by bronchial brushings during fibreoptic bronchoscopy from healthy nonatopic control subjects, were grown as previously reported $[22,35]$. The $16 \mathrm{HBE}$ cells were cultured in T75 flasks in minimal essential media with Earle's salts (Gibco BRL, Paisley, UK) supplemented with $10 \%(\mathrm{v} / \mathrm{v})$ foetal calf serum (FCS; TCS Biologicals, Buckingham, UK), 2 mM L-glutamine (Gibco BRL), $50 \mathrm{U} \cdot \mathrm{mL}^{-1}$ penicillin and $50 \mu \mathrm{g} \cdot \mathrm{mL}^{-1}$ streptomycin (Gibco BRL), whereas primary PBECs were grown in hormonally supplemented bronchial epithelial growth media (Clonetics, San Diego, CA, USA) with the primary passage 0 containing 0.5 $\mu \mathrm{g} \cdot \mathrm{mL}^{-1}$ fungizone (Gibco BRL). Cell cultures were incubated at $37^{\circ} \mathrm{C}$ in a humidified atmosphere of $5 \%(\mathrm{v} / \mathrm{v}) \mathrm{CO}_{2}$ in air. Following sequential passages of epithelial cells (passage 2 for PBECs), $\sim 1 \times 10^{5}$ cells were seeded into 24 -well culture plates (coated with $30 \mu \mathrm{g} \cdot \mathrm{mL}^{-1}$ type 1 collagen (PureCol, Inamed, Fremont, CA, USA) for PBECs) and grown to $70 \%$ confluency. The subconfluent cell monolayers were then rendered quiescent for $24 \mathrm{~h}$ in their relevant serum-free media (SFM); 16HBE cells were serum starved by culturing them with RPMI 1640 without phenol red containing $1 \%(\mathrm{v} / \mathrm{v})$ bovine serum albumin (BSA), $2 \mathrm{mM}$ L-glutamine, $50 \mathrm{U} \cdot \mathrm{mL}^{-1}$ penicillin and $50 \mu \mathrm{g} \cdot \mathrm{mL}^{-1}$ streptomycin, whereas PBECs were serum starved in bronchial epithelial basal media containing $1 \%$ insulin, transferrin and sodium selenite media supplement plus $0.3 \%$ (v/v) BSA for PBECs). To mimic the repairing and resting phenotypes, subconfluent epithelial cell cultures were incubated for $24 \mathrm{~h}$ with EGF $\left(10 \mathrm{ng} \cdot \mathrm{mL}^{-1}, 24 \mathrm{~h}\right)$ or SFM, respectively, and generated EGF-CM and basal-CM were harvested by centrifugation. Secretion of transforming growth factor- $\beta_{2}$ was increased significantly by EGF (see figure D1 in supplementary data) from $16 \mathrm{HBE}$ cells, consistent with the notion that EGF-induced repair causes release of epithelium-derived pro-fibrogenic factors [22]. The 16HBE epithelial cell CM were also analysed for GM-CSF, IL-8, $\mathrm{LTB}_{4}$ and TNF- $\alpha$ levels using commercial ELISA kits (R\&D Systems, Abingdon, UK).

\section{Analysis of neutrophil activation induced by the EGF- stimulated epithelium}

Peripheral venous blood was obtained from normal healthy donors and neutrophils were purified as previously detailed $[36,37]$ using dextran sedimentation and discontinuous plasmaPercoll $_{\mathbb{R}}$ gradients (GE Healthcare Ltd, Buckinghamshire, UK) with minor modifications. After separation, neutrophils were washed with $50 \%$ platelet-poor plasma-PBS solution, followed by Dulbecco's PBS with or without $\mathrm{Ca}^{2+}$ and $\mathrm{Mg}^{2+}$. This procedure routinely yielded $>96 \%$ pure unprimed neutrophils, with $<0.5 \%$ mononuclear cell contamination and $>98 \%$ viability, as assessed by trypan blue exclusion.

In order to assess the effects of the epithelium on the expression of cell surface markers of neutrophil activation, freshly purified neutrophils $\left(5 \times 10^{5}\right.$ cells per condition) were suspended in PBS with $\mathrm{Ca}^{2+}$ and $\mathrm{Mg}^{2+}$ and incubated with epithelial $\mathrm{CM}$ at $37^{\circ} \mathrm{C}$ for $1,5,15,30,60$ and $120 \mathrm{~min}$. PBS or $10 \mu \mathrm{M} \mathrm{N}$-formyl-methionyl-leucyl-phenylalanine (fMLP) were used as negative and positive controls, respectively. Reactions were quenched by adding $1 \mathrm{~mL}$ of ice-cold PBS, followed by immersion of tubes in ice. Cells were then washed in PBS and 
incubated for $15 \mathrm{~min}$ on ice with $10 \%$ autologous serum to block nonspecific binding sites. Specific staining was then performed with fluorochrome-coupled anti-CD16, -CD14, -CD62L, -CD11b and -CD66b monoclonal antibodies (Ab; all BD Biosciences, Oxford, UK) using fluorescence-activated cell sorting (FACS) staining buffer (FSB; $2 \%(\mathrm{v} / \mathrm{v})$ heat-inactivated FCS, $0.09 \%$ sodium azide in PBS) for $30 \mathrm{~min}$ on ice. Unbound $\mathrm{Ab}$ was removed by washing twice in FSB and cells were analysed on a FACS Calibur using Cell Quest software (both BD Biosciences). Neutrophils were identified by their forward and side-scatter characteristics and all gated cells were CD16+/CD14-. Dead cells were excluded by 7-aminoactinomycin $\mathrm{D}$, the staining of which was routinely $<5 \%$.

To assess activation further, neutrophils were stimulated with $\mathrm{CM}$ for $30 \mathrm{~min}$, the optimal time-point based on the timecourse study using flow cytometry, and assessed for secretion of myeloperoxidase (MPO) determined by the 3,3-dimethoxybenzidine method $[37,38]$. Cells $\left(10^{6}\right)$ were first suspended in PBS and then incubated at $37^{\circ} \mathrm{C}$ with SFM, EGF, basal-CM or EGF-CM. Reactions were terminated by placing the plates on ice for $5 \mathrm{~min}$ before centrifugation $\left(200 \times g\right.$ for $10 \mathrm{~min}$ at $\left.4^{\circ} \mathrm{C}\right)$. Supernatants were incubated with phosphate buffer $(\mathrm{pH}$ 6.2), $3,3^{\prime}$-dimethoxybenzidine $\left(0.2 \mathrm{mg} \cdot \mathrm{mL}^{-1}\right)$ and $\mathrm{H}_{2} \mathrm{O}_{2}(90 \mathrm{nM})$ for $30 \mathrm{~min}$ at $37^{\circ} \mathrm{C}$ and reactions were terminated by adding $2 \mathrm{mM}$ sodium azide prior to spectrophotometric detection of coloured products at an absorbance of $460 \mathrm{~nm}$ (Jenway 6505 UV/VIS spectrophotometer; Jenway, Felsted, UK). The amount of MPO released was expressed as percentage of the maximal MPO secretion obtained after stimulation with fMLP $(10 \mu \mathrm{M})$.

\section{Assessment of neutrophil chemotactic activity generated in bronchial epithelial culture}

The ability of EGF-stimulated epithelial cells to generate chemoattractants for neutrophils was first assessed using $16 \mathrm{HBE}$ and then confirmed in PBECs from healthy volunteers. The chemotactic activity was measured in a fluorescence-based chemotaxis-chamber assay using calcein-labelled neutrophils as responder cells. Purified neutrophils were resuspended in fresh chemotaxis loading buffer (Hanks' balanced salt solution containing $10 \mathrm{mM}$ HEPES (pH 7.4) and supplemented with $10 \%$ autologous serum) at a concentration of $10 \times 10^{6}$ cells $\cdot \mathrm{mL}^{-1}$, then incubated for $45 \mathrm{~min}$ at $37^{\circ} \mathrm{C}$ with $5 \mu \mathrm{M}$ Calcein $\mathrm{AM}$ (Molecular Probes Europe BV, Leiden, the Netherlands). Either $31 \mu \mathrm{L}$ of basal-CM, EGF-CM or SFM were loaded into the bottom wells of a 96-well plate chemotaxis chamber (ChemoTX ${ }_{\mathbb{B}}$ System; Neuroprobe, Gaithersburg, MD, USA). For inhibition studies, neutrophils were pretreated with the putative inhibitors (all from Calbiochem, Merck Biosciences Ltd, Nottingham, UK; CP-105696 was a gift from M. Yeadon, Pfizer Ltd, Kent, UK) for 30 mins prior to the addition to the upper wells. Subsequently, a polycarbonate filter ( $3-\mu \mathrm{m}$ pore size) was placed over the bottom chamber. Neutrophils were washed with chemotaxis buffer to eliminate nonincorporated Calcein AM and loaded $(30 \mu \mathrm{L}$, $3 \times 10^{5}$ cells $\cdot \mathrm{mL}^{-1}$ ) on top of the filter directly over each sample well in triplicate. After allowing cells to migrate at $37^{\circ} \mathrm{C}(5 \% \mathrm{v} /$ v) $\mathrm{CO}_{2}$ ) for $60 \mathrm{~min}$, the nonmigrated cells were gently aspirated and $40 \mu \mathrm{L}$ of detachment buffer (PBS supplemented with $20 \mathrm{mM}$ EDTA and $0.3 \%(\mathrm{v} / \mathrm{v})$ BSA) was applied on top of each well and incubated for $30 \mathrm{~min}$ at $4^{\circ} \mathrm{C}$. Residual neutrophils that remained on top of the filter were flushed carefully with PBS and the plate was centrifuged for $8 \mathrm{~min}$ at $120 \times g$ to collect any cells that had partially migrated through the filter. The ChemoTX $_{\circledR}$ System was disassembled gently and the bottom plates were read in an FLX 800 Microplate Fluorescence reader (Bio-Tek, Winooski, VT, USA) using $485 \mathrm{~nm}$ and $530 \mathrm{~nm}$ as the excitation and emission wavelengths, respectively. Fluorescence of migrated neutrophils was extrapolated from a standard constructed curve using known numbers of fluorescently labelled cells. The number of cells migrating in the absence of chemoattractant was subtracted to determine chemoattractantmediated chemotaxis.

\section{Analysis of signalling via Akt by Western blotting}

Neutrophils were exposed to basal-CM and EGF-CM from $16 \mathrm{HBE}$ cultures and fMLP $(10 \mu \mathrm{M})$, SFM or EGF as controls for $5 \mathrm{~min}$. Whole-cell protein lysates were then prepared from the cell pellets by solubilising in lysis buffer $(20 \mathrm{mM}$ Tris- $\mathrm{HCl}$, pH 7.8, $138 \mathrm{mM} \mathrm{NaCl}, 1 \mathrm{mM}$ EDTA, $1 \mathrm{mM}$ sodium orthovanadate, $1 \%$ Nonidet P-40 and 1\% Triton X-100) supplemented with a protease inhibitor cocktail (all reagents purchased from Sigma Aldrich, Poole, UK). Protein samples (50 $\mu \mathrm{g}$ of protein per condition) were denatured, separated by SDS-PAGE and transferred overnight onto nitrocellulose membrane by using the Mini-PROTEAN 3 apparatus (Bio-Rad Ltd, Watford, UK). Following the blocking step using PBS with 5\% skimmed milk and $0.1 \%$ Tween 20 (Sigma Aldrich) for $1 \mathrm{~h}$, the membranes were incubated with primary $\mathrm{Ab}$ at room temperature for $1 \mathrm{~h}$ with anti-phospho-Akt (Ser ${ }^{473}$ specific) monoclonal Ab (1:1,000 dilution; Cell Signaling Technology, Danvers, MA, USA). After sequential washing, the membranes were incubated for $1 \mathrm{~h}$ with the secondary Ab, a goat anti-mouse immunoglobulin $\mathrm{G}$ conjugated to horseradish peroxidase (1:2,500 dilution of stock, obtained from Sigma Aldrich). The immunoblotted membranes were visualised using Pierce ECL Western Blotting Substrate (Pierce, Cheshire, UK). For re-probing, membranes were stripped (in buffer containing $62.5 \mathrm{mM}$ Tris, $2 \%$ SDS and $0.8 \%$ (v/v) $\beta$-mercaptoethanol) for $45 \mathrm{~min}$ at $55^{\circ} \mathrm{C}$, followed by extensive washing before reblocking and re-probing with either anti-total-Akt polyclonal Ab (1:1,000 dilution; Cell Signaling Technology) or anti- $\alpha$-tubulin (1:5,000 dilution; Sigma Aldrich).

\section{Statistical analysis}

All values are expressed as mean \pm SEM from a number of separate experiments. Data were analysed using an unpaired t-test. A p-value $<0.05$ was considered statistically significant.

\section{RESULTS}

\section{Effects of epithelial culture-CM on neutrophil activation}

Control conditions, i.e. SFM and basal-CM or EGF alone (data not shown), did not significantly alter the proportion of neutrophils expressing CD11b and CD66b until 2 h (fig. 1a and b). Incubation of neutrophils in EGF-CM markedly upregulated CD11b and CD66b at $30 \mathrm{~min}(\mathrm{p}<0.001$; fig. 1a and $\mathrm{b}$ ). In parallel, CD62L expression markedly reduced within 5 min of exposure to both basal-CM and EGF-CM (fig. 1c) and followed a similar trend over $2 \mathrm{~h}$. While the rate of CD62L shedding was similar for basal-CM and EGF-CM, this was significantly different throughout the time-course when compared with control conditions. EGF-CM also induced a significant increase in MPO release $(p=0.0065)$. A further minor stimulatory effect on MPO release was observed when 

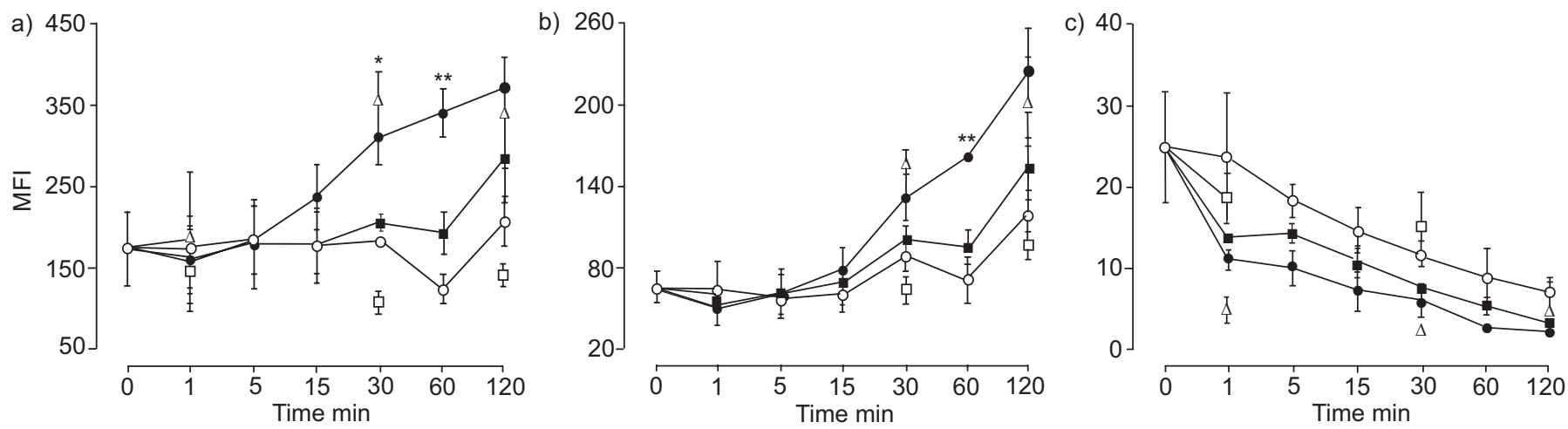

FIGURE 1. Time-course study of epidermal growth factor (EGF)-conditioned media (CM) effects on neutrophil activation marker expression in a) CD11b, b) CD66b and c) CD62L. Purified neutrophils were treated with serum-free medium $(\bigcirc)$, basal-CM $(\boldsymbol{\square})$ or EGF-CM $(\bullet)$. PBS $(\square)$ and $N$-formyl-methionyl-leucyl-phenylalanine $(10 \mu M$; $\triangle$ ) were used as negative and positive controls, respectively. Expression of neutrophil surface molecules was determined by flow cytometric analyses, as described in the Materials and methods section. Data are presented as mean \pm SEM of four independent experiments performed using neutrophils purified from blood of four different donors MFI: mean fluorescence intensity. ${ }^{*}: p<0.05 ;{ }^{* *}: p<0.01$ compared with basal-CM-treated neutrophils.

EGF-CM-treated neutrophils were compared with basal-CMtreated cells, but this difference was not statistically significant (see figure D2 in the supplementary data).

\section{Neutrophil chemotactic activity detected in epithelial culture-CM}

Both basal-CM and EGF-CM from 16HBE cells induced significant $(p<0.0001)$ neutrophil migration (fig. $2 a)$, with the effect of EGF-CM being significantly $(p=0.0043)$ greater than basal-CM, while EGF alone had no effect (fig. 2a). Whereas dose-response curves of chemotactic responses to individual chemoattractants are typically bell-shaped, assessment of responses to three dilutions of EGF-CM (1:10, 1:5 and 1:1) showed that a 1:1 dilution of the original EGF-CM induced a maximum migratory response (fig. $2 b$ ). Therefore, this dilution was chosen for all subsequent experiments. Using PBECs grown from bronchial brushings obtained from healthy volunteers, the effect of EGF on neutrophil chemotactic activity was shown to be similar, although both basal- and EGF-CM had a slightly less potent effect (fig. 2c).

\section{Signalling pathways involved in the regulation of neutrophil chemotaxis induced by an EGF-CM}

Based on previous studies [39, 40], it was hypothesised that the observed enhanced chemotactic response to EGF-CM involved activation of PI3K and its downstream signalling pathways in migrating neutrophils. Pre-treatment of neutrophils with the PI3K inhibitor, wortmannin (100 $\mathrm{nM}, 30 \mathrm{~min})$, prior to exposure to
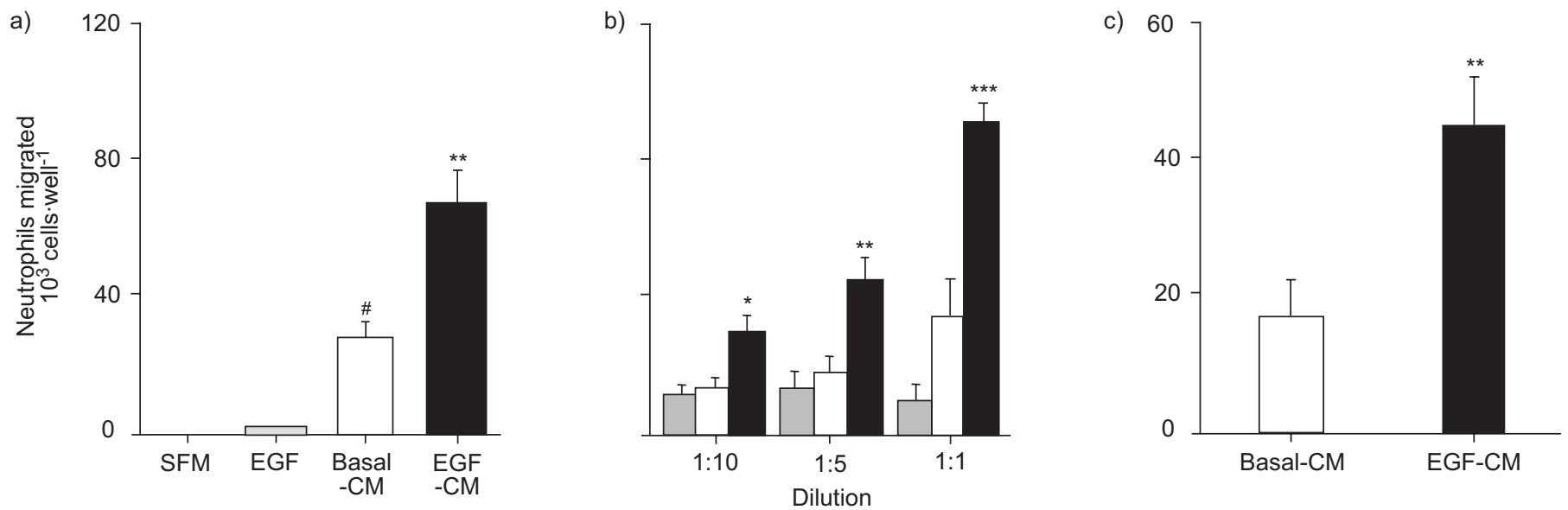

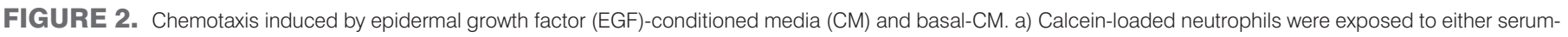

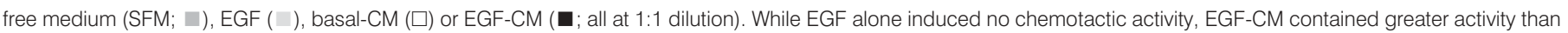

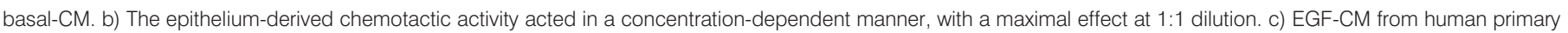

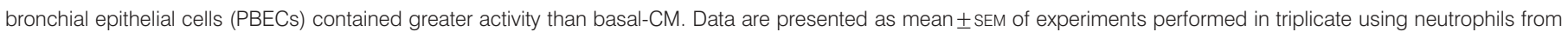

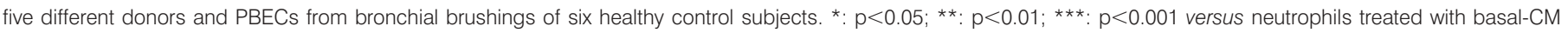
alone; ${ }^{\#}: p<0.001$ versus SFM-treated neutrophils. 

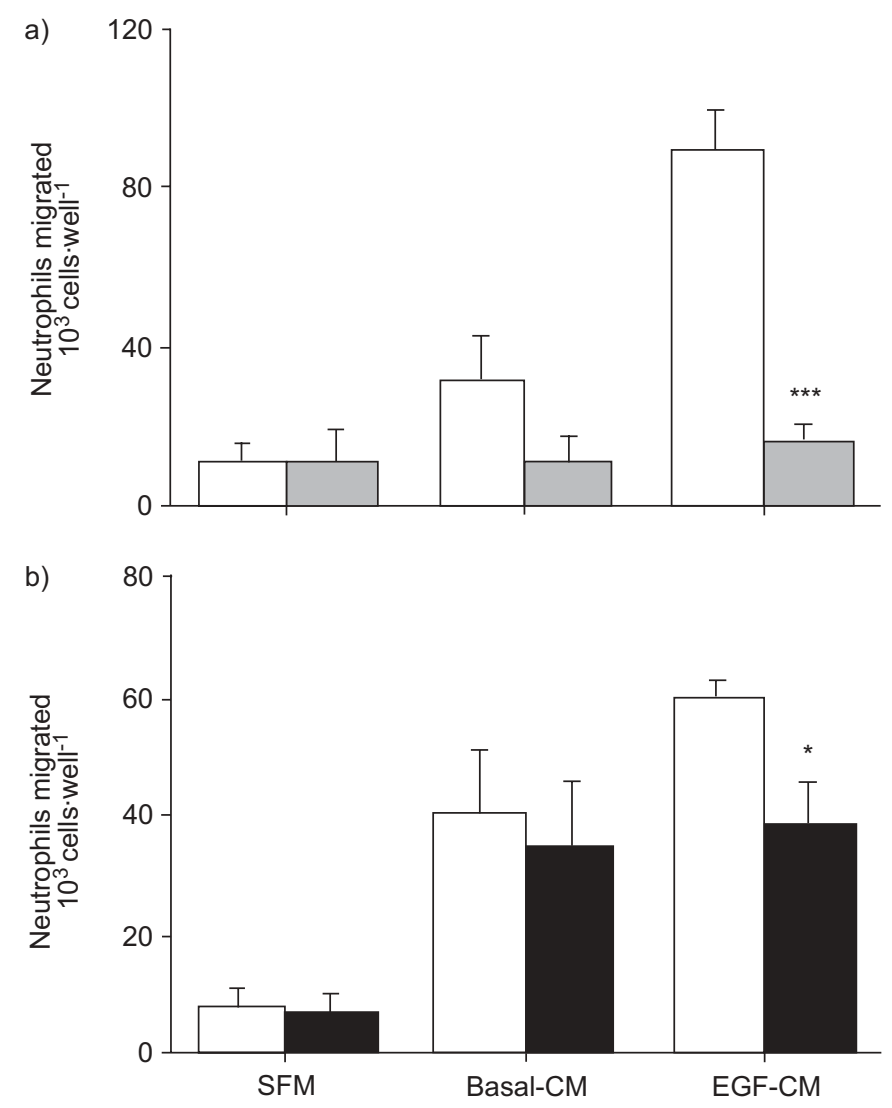

c)

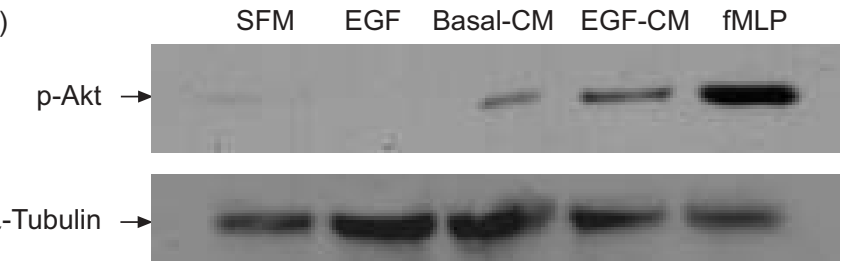

FIGURE 3. Effect of the a) phosphatidylinositol-3-kinase (PI3K) inhibitor wortmannin or b) the Akt inhibitor HIMO (1L-6-hydroxymethyl-chiro-inositol2-(R)-2O-methyl-3-O-octadecylcarbonate) on neutrophil migration induced by epidermal growth factor (EGF)-conditioned media (CM) or basal-CM. Calcein-loaded neutrophils were pre-treated with either buffer $(\square)$, wortmannin $(100 \mathrm{nM}$; $\square)$ or HIMO $(10 \mu \mathrm{M} ; \boldsymbol{n})$ for $30 \mathrm{~min}$ before exposure of cells to serum-free medium (SFM), basal-CM or EGF-CM. Data are presented as mean \pm SEM of seven and five independent experiments performed in triplicate, respectively. c) A Western blot of whole-neutrophil lysates showing that EGF-CM stimulation induces Akt phosphorylation. Purified neutrophils were stimulated with SFM, EGF, basal-CM, EGF-CM or $\mathrm{N}$-formyl-methionyl-leucyl-phenylalanine ( $\mathrm{fMLP} ; 10 \mu \mathrm{M}$ ) as a positive control at $37^{\circ} \mathrm{C}$ for $5 \mathrm{~min}$, and then lysed. Equal amounts of protein from neutrophil lysates (50 $\mu \mathrm{g}$ of lysate per lane) were run on 10\% SDS-PAGE, transferred to polyvinylidene fluoride and phosphorylated Akt ( $\mathrm{p}$-Akt) on Ser ${ }^{473}$ visualised by Western blotting. $\alpha$-Tubulin expression is shown as a loading control. A representative blot of three independent experiments is presented. ${ }^{*}: p<0.05$; ${ }^{* \star *}: p<0.001$ versus untreated controls.

EGF-CM obtained with 16HBE cells reduced chemotaxis to levels achieved with basal-CM, with no effect on basal-CM-induced migration (fig. 3a). The role of Akt, a well characterised PI3Kdependent protein kinase known to regulate various neutrophil functions, was then investigated [41,42]. While the selective Akt inhibitor, 1L-6-hydroxymethyl-chiro-inositol2-(R)-2-O-methyl-3O-octadecylcarbonate $(10 \mu \mathrm{M}, 30 \mathrm{~min})$ [43], had no effect on basal-CM-mediated chemotaxis, it significantly reduced the EGF$\mathrm{CM}$-induced migration down to levels seen with basal-CM (fig. $3 b$ ). Western blotting using a monoclonal $\mathrm{Ab}$ specific for endogenously phosphorylated Akt (Ser ${ }^{473}$ specific) produced a distinct band of $\sim 60 \mathrm{kDa}$ that corresponded to the predicted size of phosphorylated Akt (fig. 3c), with the intensity being greater in EGF-CM-stimulated cells when compared with basal-CM-treated neutrophils (fig. 3c).

Since phospholipase D (PLD) is essential for the hydrolysis of phosphatidylcholine into phosphatidic acid $(\mathrm{PtdOH})$ and subsequent participation in neutrophil function [37], it was further hypothesised that the PLD enzymatic pathway may also regulate neutrophil migration induced by EGF-conditioned epithelium. The primary alcohol, butan-1-ol (0.5\% (v/v)), which participates in a transphosphatidylation reaction by diverting specific PLD-derived PtdOH into a more stable metabolite whilst being a poor substrate for subsequent PLD-driven signalling cascades, caused significant inhibition, while, the control alcohol, butan-2-ol $(0.5 \%(\mathrm{v} / \mathrm{v}))$ had no effect (fig. $4 \mathrm{a})$.

Finally, the current authors examined whether EGF-CMmediated neutrophil chemotaxis occurs via specific members of the PI3K-related kinase family, most notably mammalian target of rapamycin (mTOR), a target substrate of the PI3K/ Akt signalling pathway [44]. Using rapamycin, which selectively inactivates mTOR, it was shown that chemotaxis induced by either EGF-CM or basal-CM was largely unaffected by a maximal inhibitory concentration $(100 \mathrm{nM})$ of this lipophilic macrolide (fig. 4b).

\section{Characterisation of neutrophil-active factors released by epithelial cells}

Initial time-course analysis of CM from $16 \mathrm{HBE}$ cells showed that IL-8 release peaked at $24 \mathrm{~h}$ (fig. 5a). Analysis of the same timepoint for the other mediators showed that, by comparison with basal-CM, EGF-conditioned epithelial cells also secreted greater quantities of GM-CSF $\left(334.8 \pm 116.83\right.$ versus $\left.85.72 \pm 13.4 \mathrm{pg} \cdot \mathrm{mL}^{-1}\right)$, TNF- $\alpha\left(54.17 \pm 11.07\right.$ versus $\left.26.07 \pm 1.9 \mathrm{pg} \cdot \mathrm{mL}^{-1} ; \mathrm{p}<0.05\right)$ and IL-8 (341.24 \pm 48.49 versus $151.5 \pm 27.29 \mathrm{pg} \cdot \mathrm{mL}^{-1} ; \mathrm{p}<0.001$; fig. $\left.5 \mathrm{~b}-\mathrm{d}\right)$. In contrast, the EGF-conditioned epithelium did not produce any more $\mathrm{LTB}_{4}$ than the control epithelium $(40.29 \pm 3.81$ and $33.11 \pm 4.9 \mathrm{pg} \cdot \mathrm{mL}^{-1}$ in basal-CM and EGF-CM, respectively; fig. 5e).

The roles of the individual neutrophil chemotaxins were studied further using neutralising antibodies and blocking agents. In preliminary experiments, chemotactic dose-responses were obtained for TNF- $\alpha$, GM-CSF, IL- 8 and $\mathrm{LTB}_{4}$ (see figure D3a-d in the supplementary data). In addition, the effects of neutralising monoclonal Abs against TNF- $\alpha$ and GM-CSF, and the selective antagonists for the IL-8 receptor, CXCR2 (SB-225002), and the $\mathrm{LTB}_{4}$ receptor, BLT1 (CP-105696), were assessed (see figure $\mathrm{D} 3 \mathrm{e}-\mathrm{h}$ in the supplementary data). Using optimal concentrations of blocking agents, the chemotactic activity in basal-CM could not be significantly inhibited by any antagonist or neutralising monoclonal $\mathrm{Ab}$ in isolation. The activity was partially, but not significantly, reduced only when either the selective BLT1 receptor antagonist or the CXCR2 antagonist were combined with monoclonal Abs for TNF- $\alpha$ or GM-CSF 

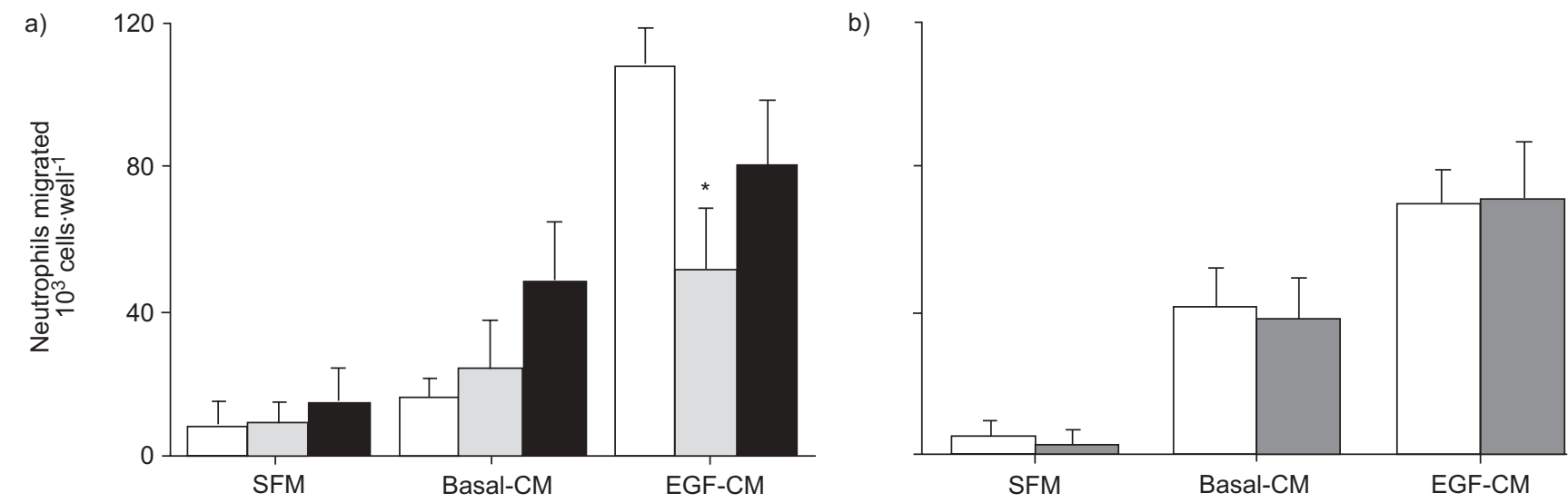

FIGURE 4. Effect of the modulators of a) phospholipase D or b) the mammalian target of rapamycin inhibitor, rapamycin, on basal-conditioned media (CM) and epidermal growth factor (EGF)-CM-triggered neutrophil migration. Calcein-loaded neutrophils $\left(10 \times 10^{6} \mathrm{cells} \cdot \mathrm{mL}^{-1}\right)$ were pre-treated with either buffer $(\square)$, butan-1-ol $(0.5 \%(\mathrm{~V} /$ $\mathrm{v})$; $)^{-}$, butan-2-ol $(0.5 \%(\mathrm{v} / \mathrm{v})$; $)$ or rapamycin $(100 \mathrm{nM}$; $)$ for 30 min before exposure of cells to serum-free medium (SFM), basal-CM or EGF-CM for 60 min at $37^{\circ} \mathrm{C}$. The number of chemoattractant-mediated neutrophils was extrapolated as detailed in the Materials and methods section. Data are presented as mean \pm SEM of four and six independent experiments performed in triplicate, respectively. ${ }^{*}: p<0.05$ versus untreated controls.

(fig. 6a). EGF-CM-mediated chemotaxis could be partially attenuated close to basal levels when the CXCR2 $(45.2 \%$ inhibition compared with control neutrophils) and BLT1 receptor $(51.2 \%$ inhibition) antagonists, or the anti-GM-CSF monoclonal $\mathrm{Ab}$ (56.3\% inhibition) were applied individually. Anti-TNF- $\alpha$ monoclonal $\mathrm{Ab}$ alone was ineffective (fig. $6 \mathrm{~b}$ ). Complete abrogation of neutrophil chemotaxis caused by EGF-CM to below basal levels (present in basal-CM) was achieved by combining anti-GM-CSF monoclonal $\mathrm{Ab}$ with either the CXCR2 or BLT1 antagonists alone or together (fig. 6b). Interestingly, the co-application of anti-TNF- $\alpha$ monoclonal $\mathrm{Ab}$ to either anti-GM-CSF monoclonal Ab or the CXCR2 and BLT1 antagonists partially reversed some of the inhibitory effects achieved with these blocking agents alone (fig. 6b).

To confirm further that the chemotactic activity present in EGF-CM involves $\mathrm{LTB}_{4}, 16 \mathrm{HBE}$ cells were cultured in the presence of the 5-lipoxygenase-activating protein (FLAP) inhibitor, MK-886 $(1 \mu \mathrm{M})$, for 30 min prior to EGF stimulation. The increase in chemotaxis towards EGF-CM was significantly attenuated by MK-886 to levels seen with basal-CM (fig. 7a), consistent with its effect on blocking 5-lipoxygenase (5-LO)mediated LTs, suggesting that LTs participated in the generation of the chemotactic activity.

Having observed that upon pre-treatment of neutrophils with CP-105696 neutrophil migration to EGF-CM was substantially reduced, it was questioned whether this was due to the BLT1 antagonist blocking the chemotactic effects of $\mathrm{LTB}_{4}$ generated by migrating neutrophils upon their initial exposure to EGFCM. Indeed, 5-LO-initiated pathways and their products, including $\mathrm{LTB}_{4}$, have been previously reported to be markedly increased in neutrophils during their migration in a murine air pouch-model of inflammation [45]. Therefore, the FLAP inhibitor, MK-886 (1 $\mu \mathrm{M}, 30 \mathrm{~min})$, was used to analyse whether neutrophil migration is mediated via autocrine release of $\mathrm{LTB}_{4}$ upon exposure to basal-CM or EGF-CM. Neutrophil migration in response to both $\mathrm{CM}$ after pre-treatment with MK-886 remained unaltered (fig. $7 \mathrm{~b}$ ). MK-886 was also ineffective in diminishing neutrophil chemotaxis towards IL-8 and $\mathrm{LTB}_{4}$ (fig. $7 \mathrm{~b}$ ), excluding the possibility of an autocrine process involving $\mathrm{LTB}_{4}$ and suggesting that steady-state levels of $\mathrm{LTB}_{4}$ can synergise with other critical mediators in EGF-CM.

\section{DISCUSSION}

Previous studies $[24,26,27]$ have shown that, when stimulated by EGF, the epithelium produces mediators that activate neutrophils, but there has been no direct evidence to link these mediators with activation and chemotaxis of neutrophils and to quantify their relative contribution. The current study presents evidence that, while a resting epithelium can influence, to an extent, neutrophil behaviour, these responses are considerably enhanced when epithelial cells are stimulated by EGF. This setting reflects a response to any type of acute or chronic epithelial damage that compromises the physical integrity of the epithelial barrier allowing exposure of EGFRs on the basolateral surface of the epithelium to ligands present in the airway lining fluid. The present study has shown that neutrophil chemotactic responses to EGF-CM are regulated through PI3K and downstream signalling pathways involving Akt and PLD but not mTOR. It also highlights that the activated epithelium possesses a greater secretory potential as it releases larger quantities of the neutrophil-active mediators, GM-CSF, IL- 8 and TNF- $\alpha$. Consequently, the inhibition of their activity resulted in complete abrogation of the additional chemotactic activity that the EGF-conditioned epithelium produces over and above levels seen with a resting epithelium. Finally, the current authors have also demonstrated that while $\mathrm{LTB}_{4}$ release by the activated epithelium is not raised relative 

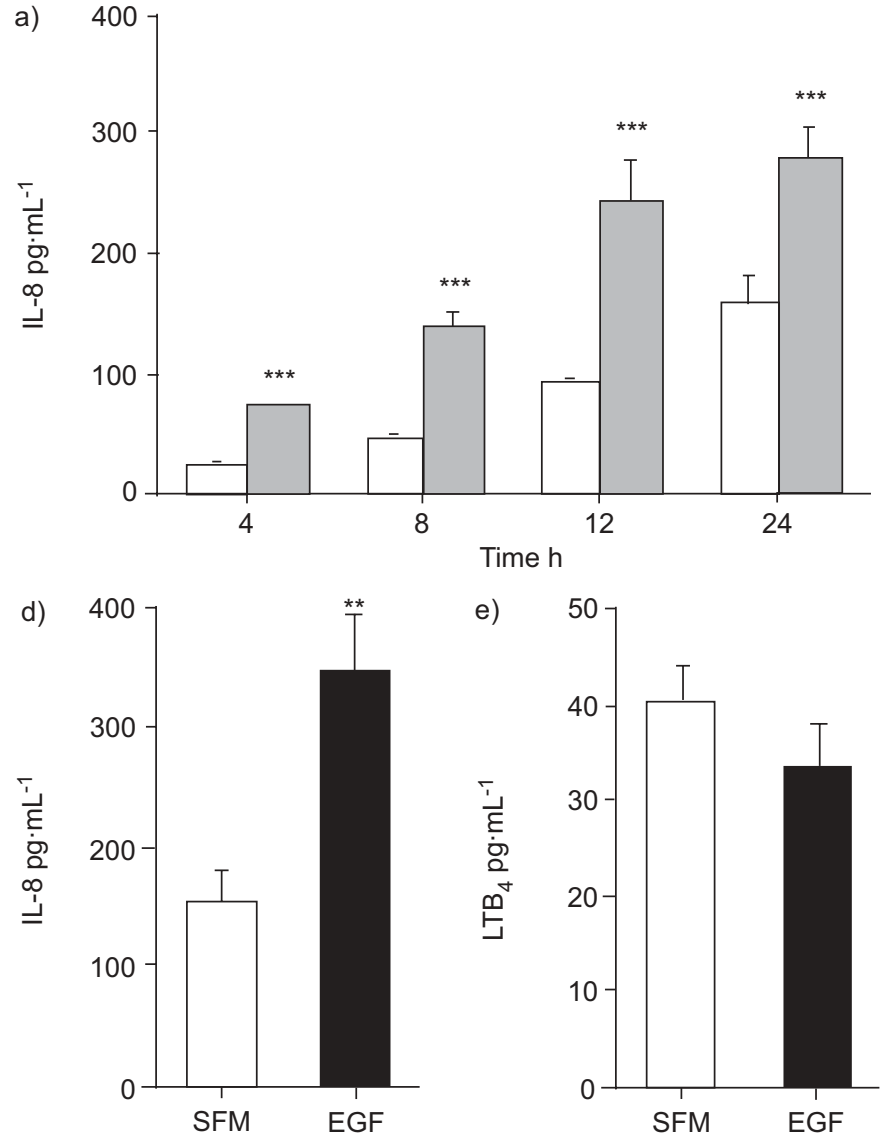

to the basal epithelium, it acts to potentiate the chemotactic responses of the other pro-inflammatory mediators present in EGF-CM. Taken together, the results of this study show that the epithelium has a significant potential to enhance neutrophil function when driven into a repair mode, a phenotype that is seen after acute (e.g. viral infection) or chronic (e.g. asthma) lung injury.

The present study demonstrates for the first time that the activated epithelium can upregulate CD11b and CD66b, and reduce CD62L expression on neutrophils. Neutrophils utilise such processes in the acute setting when enhanced neutrophil function is beneficial at a time when the epithelial barrier is compromised. Following restoration of the epithelial barrier, EGF in the mucosal lining fluid is unable to stimulate basolaterally localised EGFRs in the pseudostratified columnar bronchial epithelium. If, however, the insult is excessive and/or chronic and does not allow complete repair, EGF-mediated epithelial activation will persist, causing sustained neutrophil activation with the potential to cause further tissue damage $[5,7$, 10, 46]. A pivotal role of EGF in repair processes has been demonstrated in inflammatory bowel diseases [47, 48], renal injury [49], psoriasis [47, 50] and corneal damage [47, 51]. While these disorders also have a significant neutrophilic component, the association between EGF-mediated epithelial repair and neutrophil activation and recruitment has not been explored in detail. Hence, the demonstration of EGF modulatory effects in human PBECs herein complements and extends previous
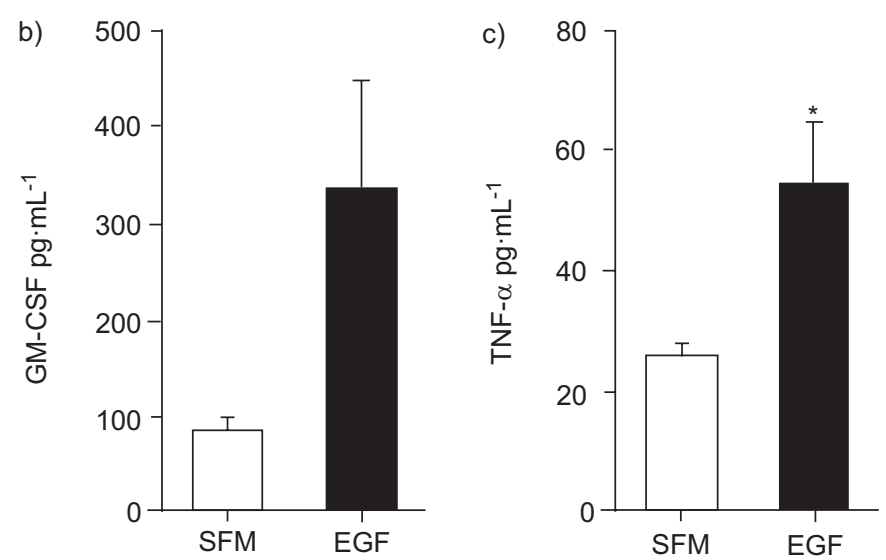

FIGURE 5. Treatment of human bronchial epithelial (16HBE) cells with epidermal growth factor (EGF) upregulates epithelium-derived mediator release. a) Time-course of interleukin (IL)-8 production measured by ELISA in conditioned media (CM) harvested at the indicated time-points after stimulation of $16 \mathrm{HBE}$ cells with serum-free medium (SFM; $\square$ ) or EGF $(10 \mathrm{ng} \cdot \mathrm{mL} ; \square)$. The CM were also analysed for b) granulocyte-macrophage colony-stimulating factor (GM-CSF), c) tumour necrosis factor (TNF)- $\alpha, d)$ IL-8 and e) leukotriene (LT)B $B_{4}$ secretion at the 24-h time-point. Apart from $\mathrm{LTB}_{4}$, the levels of all mediators detected in EGF-treated cells (ם) were considerably higher than from SFM-treated cells ( $\square$ ). Data are presented as mean \pm SEM of four to nine separate experiments, each performed in duplicate. ${ }^{*}: p<0.05,{ }^{* *}: p<0.01,{ }^{* * *}: \mathrm{p}<0.001$ versus SFM-treated controls.

observations [24, 25], further implicating interaction between the repairing bronchial epithelium and neutrophils as a mechanism of neutrophil-mediated tissue damage.

In agreement with previous reports of neutrophil migration induced by various chemoattractants [39, 40], a role for PI3K signalling in the activation and migration of neutrophils induced by an EGF-conditioned epithelium was demonstrated. Likewise, EGF-CM-mediated neutrophil chemotaxis also involved enhanced activity of Akt downstream of PI3K and the PLD signalling pathway, with the latter finding being consistent with the report by LEHMAN et al. [52]. However, selective inhibition of mTOR did not affect the migratory responses to either basal-CM or EGF-CM, which is surprising given the reports by GOMEZ-CAMBRONERO [44] that neutrophil migration induced by GM-CSF is dependent on mTOR. This apparent discrepancy may arise because of regulation of neutrophil chemotaxis occurring via an mTOR component that is resistant to rapamycin treatment. This premise is based on observations in various mammalian cell types that mTOR can remain functionally active even after rapamycin treatment [53, 54]. This large protein kinase exists in two distinct complexes: one contains mTOR, G $\beta$ L and raptor, and can be inhibited by rapamycin [55], while the other contains mTOR, G $\beta \mathrm{L}$ and rictor, and is rapamycin insensitive [53, 55]. The cellular function of the latter complex is only beginning to be unravelled [53] and the current study did not address the question of whether the rictor-mTOR complex regulates the 

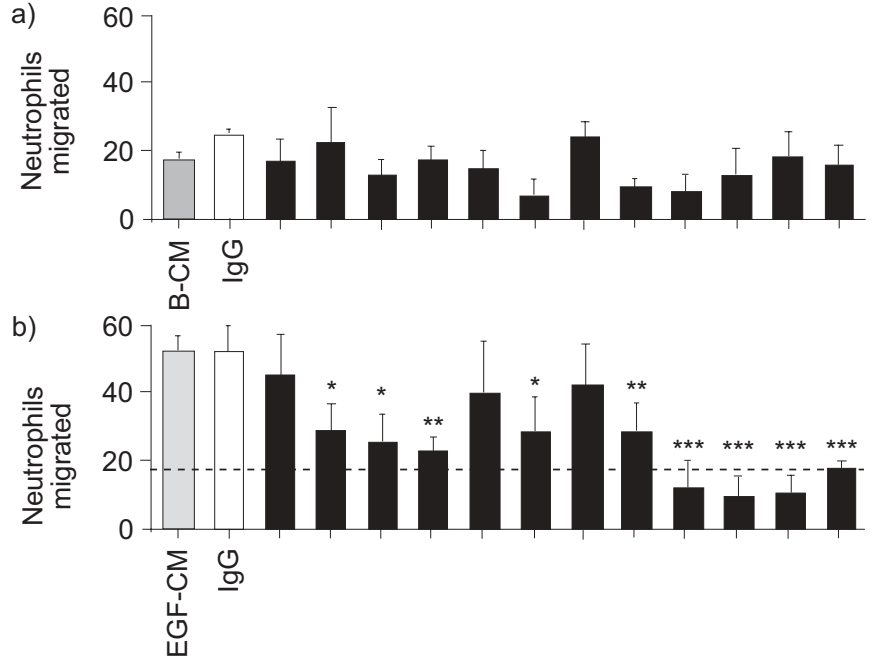

$\begin{array}{llllllllllllll}\text { Anti-TNF- } \alpha \text { mAb } & + & - & - & - & + & + & + & + & - & - & - & + \\ \text { CXCR2 antagonist } & - & + & - & - & + & - & - & + & + & - & + & + \\ \text { BLT1 antagonist } & - & - & + & - & - & + & - & + & - & + & + & + \\ \text { Anti-GM-CSF mAb } & - & - & - & + & - & - & + & - & + & + & + & +\end{array}$

FIGURE 6. Neutralisation/blockade of epithelial-derived mediator activity

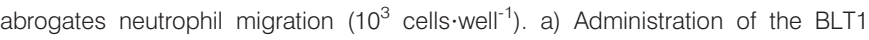
antagonist, CP-105696 $(10 \mu \mathrm{M})$ or the CXCR2 antagonist, SB-225002 (100 nM), along with the anti-tumour necrosis factor (TNF)- $\alpha$ monoclonal antibody (mAb; $100 \mu \mathrm{g} \cdot \mathrm{mL}^{-1}$ ) or anti-granulocyte-macrophage colony-stimulated factor (GM-CSF) $\mathrm{mAb}\left(100 \mu \mathrm{g} \cdot \mathrm{mL}^{-1}\right)$, partially attenuated basal (B)-conditioned media (CM)mediated chemotaxis compared with the untreated control neutrophils b) Complete abrogation of the chemotactic activity exerted by epidermal growth factor (EGF)-CM on neutrophils was achieved down to basal levels (- - - - ) with the combination of anti-GM-CSF mAb with SB-225002 and/or CP-105696. Data are presented as mean \pm SEM of five independent experiments performed in triplicate using peripheral blood neutrophils isolated from different donors. Ig: immunoglobulin. *: $p<0.05 ; * *: p<0.01 ; * * *: p<0.001$ versus untreated EGF-CM control. observed rapamycin-insensitive chemotaxis in response to basal-CM and EGF-CM.

The present authors found that bronchial epithelial cells increase GM-CSF, IL- 8 and TNF- $\alpha$ production when stimulated by EGF. Using selective inhibitors, it was possible to dissect the relative contributions of these epithelium-derived factors and to show synergy between individual mediators. It has been reported previously that neutrophilic chemotaxins, such as IL8 , are markedly upregulated in the altered epithelial phenotype in asthma [24]. A more recent study [27] has shown that the EGFR pathway is involved in stimulating IL-8 production in airway epithelial cells via a novel signalling cascade involving activation of TNF- $\alpha$ converting enzyme by dual oxidase 1 . However, this chemokine is unlikely to be solely responsible for driving epithelial-mediated neutrophil migration as the present data clearly show that when the selective antagonist for the CXCR2 receptor (SB-225002) was applied individually, it failed to completely abrogate neutrophil chemotaxis evoked by EGF-CM (fig. 6b). Furthermore, EGF significantly upregulated secretion of GM-CSF and the observed chemotactic responses were sensitive to both the neutralising anti-GM-CSF monoclonal $\mathrm{Ab}$ and the selective BLT1 antagonist, suggesting that these two mediators have independent effects on the mediation of EGF-CM-driven chemotaxis.

Bronchial epithelial cells have been previously shown to generate biologically active $\mathrm{LTB}_{4}[56,57]$. A recent study has shown that both $16 \mathrm{HBE}$ cells and PBECs constitutively express 5-LO, FLAP and $\mathrm{LTA}_{4}$ hydrolase at the mRNA and protein levels [58]. As detected by ELISA and confirmed by reversephase high-performance liquid chromatography purification, the amounts of $\mathrm{LTB}_{4}$ released over $6 \mathrm{~h}$ by stimulated $16 \mathrm{HBE}$ cells (119 pg per $10^{6}$ cells) were essentially similar to $\mathrm{LTB}_{4}$ levels of $30 \mathrm{pg}$ per $10^{5}$ cells detected at $24 \mathrm{~h}$ in the current
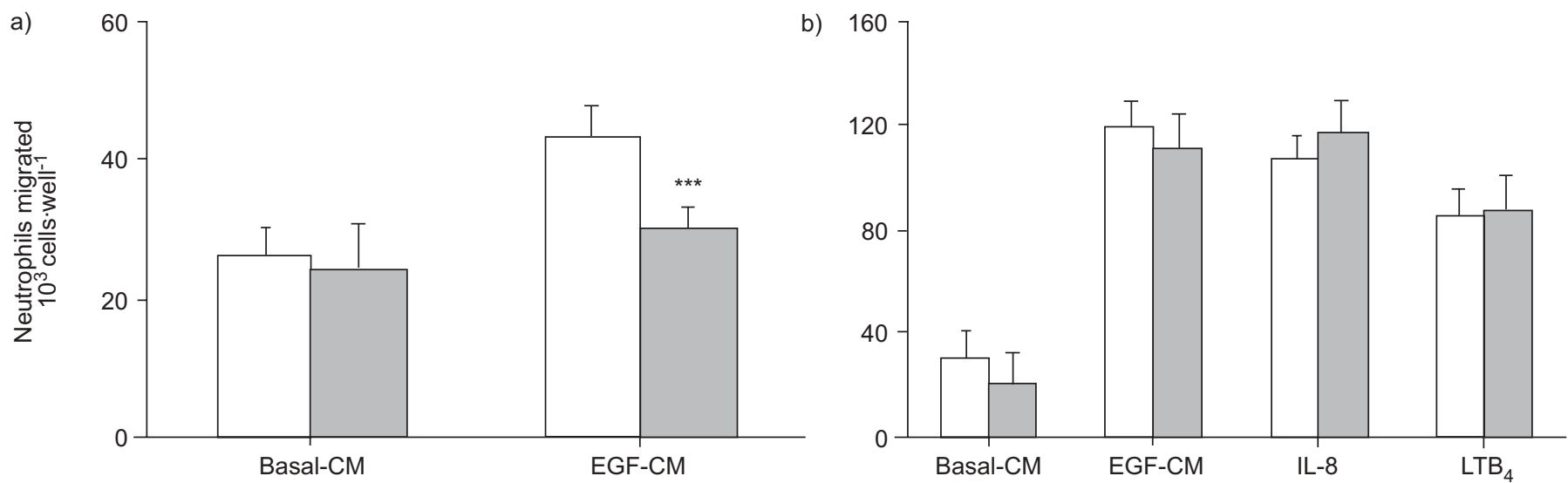

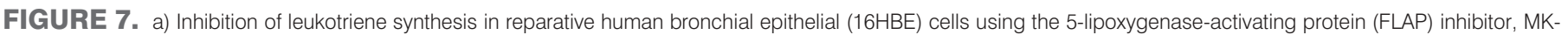

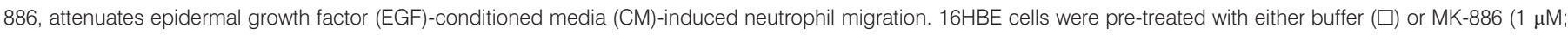

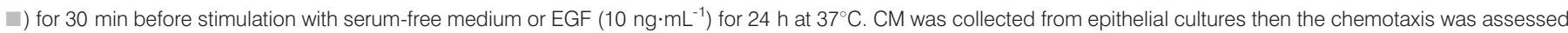

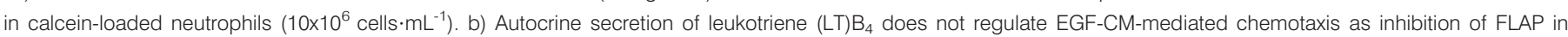

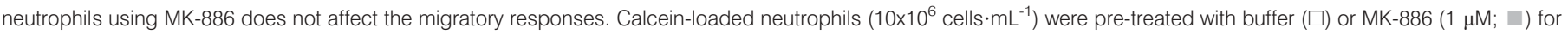

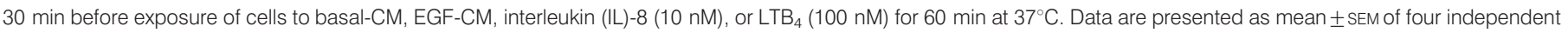
experiments performed in triplicate using neutrophils purified from blood of different donors. ${ }^{* \star}$ : $p<0.001$ versus untreated controls. 
study. Both recent data [58] and the current study show that $\mathrm{LTB}_{4}$ can be significantly reduced by pre-treatment with the specific FLAP inhibitor MK-886, confirming the authenticity of the measured $\mathrm{LTB}_{4}$. The current study further demonstrated bioactivity of the $\mathrm{LTB}_{4}$ released by $16 \mathrm{HBE}$ cells because selective blockade of the BLT1 receptor using CP-105696 significantly reduced EGF-CM-mediated chemotaxis and this LT was also able to potentiate the effects of the other chemotactic factors present in EGF-CM (fig. 6b). Of note, the subnanomolar concentrations of $\mathrm{LTB}_{4}$ present in EGF-CM $\left(\sim 30 \mathrm{pg} \cdot \mathrm{mL}^{-1}\right.$, as detected by ELISA; fig. $\left.5 \mathrm{e}\right)$ were at an adequate level to induce chemotaxis of human neutrophils [59]. Comparison of the results obtained with basal-CM and those with EGF-CM showed no differences in amounts of $\mathrm{LTB}_{4}$ release, indicating that EGF is not capable of modifying the spontaneous release of $\mathrm{LTB}_{4}$ from human PBECs described previously, at least in 24-h cultures.

In conclusion, this is the first in-depth elucidation of direct modulatory effects of an epidermal growth factor-conditioned epithelium on human neutrophil activation and migration. The current authors speculate that while epidermal growth factor has the capacity to enhance neutrophilic innate immunogenicity during acute lung damage (e.g. viral injury), an aberration of these responses may be pathological in the context of chronic diseases (e.g. severe neutrophilic, forms of asthma) where bronchial epithelial damage is a common feature.

\section{ACKNOWLEDGEMENTS}

The authors would like to thank J.E. Collins for providing the anti-phospho-Akt (Ser ${ }^{473}$ specific) antibody, and S.A. Martin, P. Lackie, C. Moldes, K. Staples and J. Ward for their technical support and advice (all from the IIR Division, University of Southampton School of Medicine, Southampton, UK).

\section{REFERENCES}

1 Nathan C. Points of control in inflammation. Nature 2002; 420: 846-852.

2 Kishimoto TK, Jutila MA, Berg EL, Butcher EC. Neutrophil Mac-1 and MEL-14 adhesion proteins inversely regulated by chemotactic factors. Science 1989; 245: 1238-1241.

3 Condliffe AM, Chilvers ER, Haslett C, Dransfield I. Priming differentially regulates neutrophil adhesion molecule expression/function. Immunology 1996; 89: 105-111.

4 Stocks SC, Ruchaud-Sparagano MH, Kerr MA, Grunert F, Haslett C, Dransfield I. CD66: role in the regulation of neutrophil effector function. Eur J Immunol 1996; 26: 2924-2932.

5 MacNee W, Selby C. New perspectives on basic mechanisms in lung disease. 2. Neutrophil traffic in the lungs: role of haemodynamics, cell adhesion, and deformability. Thorax 1993; 48: 79-88.

6 Berton G, Yan SR, Fumagalli L, Lowell CA. Neutrophil activation by adhesion: mechanisms and pathophysiological implications. Int J Clin Lab Res 1996; 26: 160-177.

7 Louis R, Lau LC, Bron AO, Roldaan AC, Radermecker M, Djukanović $R$. The relationship between airways inflammation and asthma severity. Am J Respir Crit Care Med 2000; 161: 9-16.
8 MacNee W. Pulmonary neutrophil kinetics. Clin Phys Physiol Meas 1990; 11: Suppl. A, 133-139.

9 Barnes PJ. Mechanisms in COPD: differences from asthma. Chest 2000; 117: Suppl. 2, 10S-14S.

10 Louis R, Djukanović R. Is the neutrophil a worthy target in severe asthma and chronic obstructive pulmonary disease? Clin Exp Allergy 2006; 36: 563-567.

11 Barnes PJ. A new approach to the treatment of asthma. New Engl J Med 1989; 321: 1517-1527.

12 Wenzel SE, Szefler SJ, Leung DY, Sloan SI, Rex MD, Martin RJ. Bronchoscopic evaluation of severe asthma. Persistent inflammation associated with high dose glucocorticoids. Am J Respir Crit Care Med 1997; 156: 737-743.

13 Jatakanon A, Uasuf C, Maziak W, Lim S, Chung KF, Barnes PJ. Neutrophilic inflammation in severe persistent asthma. Am J Respir Crit Care Med 1999; 160: 1532-1539.

14 Carroll N, Carello S, Cooke C, James A. Airway structure and inflammatory cells in fatal attacks of asthma. Eur Respir J 1996; 9: 709-715.

15 Teran LM, Campos MG, Begishvilli BT, et al. Identification of neutrophil chemotactic factors in bronchoalveolar lavage fluid of asthmatic patients. Clin Exp Allergy 1997; 27: 396-405.

16 Vachier I, Bonnans C, Chavis C, et al. Severe asthma is associated with a loss of LX4, an endogenous antiinflammatory compound. J Allergy Clin Immunol 2005; 115: 55-60.

17 Wenzel SE, Larsen GL, Johnston K, Voelkel NF, Westcott JY. Elevated levels of leukotriene C4 in bronchoalveolar lavage fluid from atopic asthmatics after endobronchial allergen challenge. Am Rev Respir Dis 1990; 142: 112-119.

18 Bodey KJ, Semper AE, Redington $\mathrm{AE}$, et al. Cytokine profiles of BAL T-cells and T-cell clones obtained from human asthmatic airways after local allergen challenge. Allergy 1999; 54: 1083-1093.

19 Cotter TP, Hood PP, Costello JF, Sampson AP. Exposure to systemic prednisolone for 4 hours reduces ex vivo synthesis of GM-CSF by bronchoalveolar lavage cells and blood mononuclear cells of mild allergic asthmatics. Clin Exp Allergy 1999; 29: 1655-1662.

20 Howarth PH, Babu KS, Arshad HS, et al. Tumour necrosis factor $(\mathrm{TNF}-\alpha)$ as a novel therapeutic target in symptomatic corticosteroid dependent asthma. Thorax 2005; 60: 1012-1018.

21 Davies DE, Polosa R, Puddicombe SM, Richter A, Holgate ST. The epidermal growth factor receptor and its ligand family: their potential role in repair and remodelling in asthma. Allergy 1999; 54: 771-783.

22 Puddicombe SM, Polosa R, Richter A, et al. Involvement of the epidermal growth factor receptor in epithelial repair in asthma. FASEB J 2000; 14: 1362-1374.

23 Shim JJ, Dabbagh K, Ueki IF, et al. IL-13 induces mucin production by stimulating epidermal growth factor receptors and by activating neutrophils. Am J Physiol Lung Cell Mol Physiol 2001; 280: L134-L140.

24 Hamilton LM, Torres-Lozano C, Puddicombe SM, et al. The role of the epidermal growth factor receptor in sustaining neutrophil inflammation in severe asthma. Clin Exp Allergy 2003; 33: 233-240. 
25 Hamilton LM, Puddicombe SM, Dearman RJ, et al. Altered protein tyrosine phosphorylation in asthmatic bronchial epithelium. Eur Respir J 2005; 25: 978-985.

26 Richter A, O'Donnell RA, Powell RM, et al. Autocrine ligands for the epidermal growth factor receptor mediate interleukin-8 release from bronchial epithelial cells in response to cigarette smoke. Am J Respir Cell Mol Biol 2002; 27: 85-90.

27 Nakanaga T, Nadel JA, Ueki IF, Koff JL, Shao MX. Regulation of interleukin-8 via an airway epithelial signaling cascade. Am J Physiol Lung Cell Mol Physiol 2007; 292: L1289-L1296.

28 Vignola AM, Chanez P, Chiappara G, et al. Transforming growth factor- $\beta$ expression in mucosal biopsies in asthma and chronic bronchitis. Am J Respir Crit Care Med 1997; 156: 591-599.

29 Monick MM, Cameron K, Staber J, et al. Activation of the epidermal growth factor receptor by respiratory syncytial virus results in increased inflammation and delayed apoptosis. J Biol Chem 2005; 280: 2147-2158.

30 Lordan JL, Bucchieri F, Richter A, et al. Cooperative effects of Th2 cytokines and allergen on normal and asthmatic bronchial epithelial cells. J Immunol 2002; 169: 407-414.

31 Cox G, Gauldie J, Jordana M. Bronchial epithelial cellderived cytokines (G-CSF and GM-CSF) promote the survival of peripheral blood neutrophils in vitro. Am J Respir Cell Mol Biol 1992; 7: 507-513.

32 Cozens AL, Yezzi MJ, Kunzelmann $\mathrm{K}$, et al. CFTR expression and chloride secretion in polarized immortal human bronchial epithelial cells. Am J Respir Cell Mol Biol 1994; 10: 38-47.

33 Ehrhardt C, Kneuer C, Fiegel J, et al. Influence of apical fluid volume on the development of functional intercellular junctions in the human epithelial cell line 16HBE14o-: implications for the use of this cell line as an in vitro model for bronchial drug absorption studies. Cell Tissue Res 2002; 308: 391-400.

34 Manford F, Tronde A, Jeppsson AB, Patel N, Johansson F, Forbes B. Drug permeability in 16HBE140- airway cell layers correlates with absorption from the isolated perfused rat lung. Eur J Pharm Sci 2005; 26: 414-420.

35 Bucchieri F, Puddicombe SM, Lordan JL, et al. Asthmatic bronchial epithelium is more susceptible to oxidantinduced apoptosis. Am J Respir Cell Mol Biol 2002; 27: 179-185.

36 Haslett C, Guthrie LA, Kopaniak MM, Johnston RB Jr, Henson PM. Modulation of multiple neutrophil functions by preparative methods or trace concentrations of bacterial lipopolysaccharide. Am J Pathol 1985; 119: 101-110.

37 Cadwallader KA, Uddin M, Condliffe AM, et al. Effect of priming on activation and localization of phospholipase D1 in human neutrophils. Eur J Biochem 2004; 271: 2755-2764.

38 Henson PM, Zanolari B, Schwartzman NA, Hong SR. Intracellular control of human neutrophil secretion. I. C5ainduced stimulus-specific desensitization and the effects of cytochalasin B. J Immunol 1978; 121: 851-855.

39 Sasaki T, Irie-Sasaki J, Jones RG, et al. Function of PI3K $\gamma$ in thymocyte development, $\mathrm{T}$ cell activation, and neutrophil migration. Science 2000; 287: 1040-1046.

40 Knall C, Worthen GS, Johnson GL. Interleukin 8-stimulated phosphatidylinositol-3-kinase activity regulates the migration of human neutrophils independent of extracellular signalregulated kinase and p38 mitogen-activated protein kinases. Proc Natl Acad Sci USA 1997; 94: 3052-3057.

41 Hannigan M, Zhan L, Li Z, Ai Y, Wu D, Huang CK. Neutrophils lacking phosphoinositide 3-kinase $\gamma$ show loss of directionality during $N$-formyl-Met-Leu-Phe-induced chemotaxis. Proc Natl Acad Sci USA 2002; 99: 3603-3608.

42 Klein JB, Rane MJ, Scherzer JA, et al. Granulocytemacrophage colony-stimulating factor delays neutrophil constitutive apoptosis through phosphoinositide 3-kinase and extracellular signal-regulated kinase pathways. J Immunol 2000; 164: 4286-4291.

$43 \mathrm{Hu}$ Y, Qiao L, Wang S, et al. 3-(Hydroxymethyl)-bearing phosphatidylinositol ether lipid analogues and carbonate surrogates block PI3-K, Akt, and cancer cell growth. J Med Chem 2000; 43: 3045-3051.

44 Gomez-Cambronero J. Rapamycin inhibits GM-CSFinduced neutrophil migration. FEBS Lett 2003; 550: 94-100.

45 Levy BD, Clish CB, Schmidt B, Gronert K, Serhan CN. Lipid mediator class switching during acute inflammation: signals in resolution. Nat Immunol 2001; 2: 612-619.

46 Weiss SJ. Tissue destruction by neutrophils. N Engl J Med 1989; 320: 365-376.

47 Schultz G, Rotatori DS, Clark W. EGF and TGF- $\alpha$ in wound healing and repair. J Cell Biochem 1991; 45: 346-352.

48 Beck PL, Podolsky DK. Growth factors in inflammatory bowel disease. Inflamm Bowel Dis 1999; 5: 44-60.

49 Strutz F, Neilson EG. New insights into mechanisms of fibrosis in immune renal injury. Springer Semin Immunopathol 2003; 24: 459-476.

50 Tomic-Canic M, Komine M, Freedberg IM, Blumenberg M. Epidermal signal transduction and transcription factor activation in activated keratinocytes. J Dermatol Sci 1998; 17: 167-181.

51 Joyce NC, Joyce SJ, Powell SM, Meklir B. EGF and PGE2: effects on corneal endothelial cell migration and monolayer spreading during wound repair in vitro. Curr Eye Res 1995; 14: 601-609.

52 Lehman N, Di Fulvio M, McCray N, Campos I, Tabatabaian F, Gomez-Cambronero J. Phagocyte cell migration is mediated by phospholipases PLD1 and PLD2. Blood 2006; 108: 3564-3572.

53 Sarbassov DD, Ali SM, Kim DH, et al. Rictor, a novel binding partner of $\mathrm{mTOR}$, defines a rapamycin-insensitive and raptor-independent pathway that regulates the cytoskeleton. Curr Biol 2004; 14: 1296-1302.

54 Constantinou C, Clemens MJ. Regulation of the phosphorylation and integrity of protein synthesis initiation factor eIF4GI and the translational repressor 4E-BP1 by $\mathrm{p} 53$ Oncogene 2005; 24: 4839-4850.

55 Loewith R, Jacinto E, Wullschleger S, et al. Two TOR complexes, only one of which is rapamycin sensitive, have distinct roles in cell growth control. Mol Cell 2002; 10: 457-468.

56 Koyama S, Rennard SI, Robbins RA. Bradykinin stimulates bronchial epithelial cells to release neutrophil and monocyte chemotactic activity. Am J Physiol 1995; 269: L38-L44.

57 Behera AK, Kumar M, Matsuse H, Lockey RF, Mohapatra SS Respiratory syncytial virus induces the expression of 5lipoxygenase and endothelin-1 in bronchial epithelial cells. Biochem Biophys Res Commun 1998; 251: 704-709. 
58 Jame AJ, Lackie PM, Cazaly AM, et al. Human bronchial epithelial cells express an active and inducible biosynthetic pathway for leukotrienes B4 and C4. Clin Exp Allergy 2007; 37: 880-892.
59 Ford-Hutchinson AW, Bray MA, Doig MV, Shipley ME, Smith MJ. Leukotriene B, a potent chemokinetic and aggregating substance released from polymorphonuclear leukocytes. Nature 1980; 286: 264-265. 